\title{
ARTICLE
}

\section{Early intervention in psychosis: clinical aspects of treatment ${ }^{\dagger}$}

\author{
Brendan P. Murphy \& Warrick J. Brewer
}

Brendan Murphy is a consultant psychiatrist and Clinical Director of the Recovery and Prevention of Psychosis Service in Melbourne and Associate Professor at

Monash University, Australia. He has established a research programme investigating medical comorbidity, negative symptoms, novel treatments and genetic epidemiology of psychosis, and has an interest in neurotrophins and the autoimmune aetiology of the disorder. He is currently developing a fully integrated youth service. Warrick Brewer is Associate Professor and Principal Research Fellow in Neuropsychology at Orygen Youth Health Research Centre, Neuropsychology Research Unit, University of Melbourne. $\mathrm{He}$ is also the specialist clinical consultant for the EPPIC Intensive Case Management subprogramme. His primary research interests include using olfactory measures to identify neurodevelopmental risk of pathology, with an emphasis on psychosis and antisocial personality disorder. Correspondence Associate Professor Brendan P. Murphy, Early in Life Mental Health Service, Community Services Building, 145 Cleeland Street, Dandenong, Victoria, Australia, 3175.Email: brendan.murphy@ monash.edu

${ }^{\dagger}$ For a companion article and related Editorial see pp. $401-7$ and 398-400, this issue.

\begin{abstract}
SUMMARY
Engaging patients in first-episode psychosis services is critical in maximising the effect of early intervention and establishing a framework for longer-term treatment. Biopsychosocial assessments determine a working diagnosis and inform evidence-based treatment. Atypical antipsychotics should be used at doses that maximise therapeutic benefit and adherence while minimising sideeffects. Patients are helped to construct a narrative of their illness, including a shared understanding of the contribution of biological and environmental risks, and early warning signs. Common comorbid conditions, including depression, suicidal ideation, substance misuse and anxiety, should be addressed. Management of comorbid borderline and antisocial personality disorders is difficult; their nexus with psychosis is discussed. Cognitive-behavioural therapy is a mainstay of treatment, with specific interventions developed for problems typical in first-episode presentations. Core psychosocial interventions include psychoeducation, vocational and educational support, family interventions and multimodal group programmes.
\end{abstract}

\section{DECLARATION OF INTEREST}

B.P.M. has received research support from Diabetes Australia, the Australian Heart Foundation, Eli Lilly and Sanofi; participated in clinical trials sponsored by Sanofi, Eli Lilly, AstraZeneca, Jannsen-Cilag and Lundbeck; and been a speaker for Bristol-Myers Squibb, Lundbeck and Pfizer. W.J.B. is supported by a National Health and Medical Research Council Career Development Award and the Colonial Foundation, and has received research support from Janssen-Cilag and Eli Lilly.

The first episode of psychosis most commonly occurs in young people (15-25 years of age) (Amminger 2006) and it is often an extremely traumatic experience for patients and families. Pathways to care can be complex. Here we assume access to a specialised first-episode psychosis service such as those discussed in our previous article in this issue (Murphy 2011).

\section{Assessment}

Initial service response is critical in establishing long-term engagement and adherence. Ideally, the first assessment should be performed by a firstepisode psychosis service, but in reality patients often present out of hours and are seen by crisis assessment teams. All individuals suspected of a first episode of psychosis should be subsequently referred to the local first-episode psychosis service for primary or secondary consultation. In the absence of a specialised prodrome clinic, those with suspected prodromal symptoms should be referred back to primary care with clear pathways for secondary consultation and re-referral delineated.

\section{Encouraging engagement with services}

Effective intervention as early as possible can prevent disruption of key developmental tasks, in addition to reducing the duration of untreated psychosis (DUP), which may critically improve prognosis (McGorry 2006). Striking a balance between minimising the DUP and engaging the young person is often at the forefront of treatment pathways, especially in those reluctant to take medication. Historically, this has been resolved with coercive responses, including restraint, seclusion, parenteral antipsychotic treatment, use of the Mental Health Act and the use of police to facilitate hospital admission. Such measures traumatise the young person, and compromise engagement and adherence. Although it may be necessary to resort to such acute measures at times, engaging patients and their families during the initial assessment period can provide a foundational framework for optimising an ongoing therapeutic alliance and reduce the need for a traumatic entry into treatment.

In engaging young people, it is important to understand that normal adolescent behaviour is unstable and characterised by novelty-seeking, risk-taking and peer-directed social interactions that foster the development of adult independence (Spear 2000). These processes occur more rapidly than the development of executive skills, leading to a mismatch between drive and self-regulation (Steinberg 2005). Psychosis exacerbates this normal instability, increasing the risk of difficult and challenging behaviour during assessment (McCutcheon 2007). By maximising the patient's perceived sense of control, their drive can be 
harnessed into sensible decision-making (Brewer 2006a). This can be achieved by a number of techniques (Box 1), which should be maintained throughout treatment. Persistence reflects commitment and containment and can reap rewards with poorly engaged (or disengaged) patients; multiple non-attendance or loss to follow-up should lead to an increased service response rather than to discharge.

\section{Reaching and revealing the diagnosis}

Patients often present to services before meeting specific categorical diagnoses. For this reason, the term 'first-episode psychosis' should be used during the assessment and engagement period. This has the advantage of benignity relative to a diagnosis such as schizophrenia. The term covers a range of conditions and is useful during the early period of illness when there is diagnostic uncertainty.

A full biopsychosocial assessment, with close regard to phenomenology and the presence or absence of risk factors for particular illnesses, should be undertaken to guide the clinician towards a working diagnosis. Assessment should include investigations to exclude rarer organic causes of psychosis where indicated. A review by a consultant psychiatrist should take place as early as possible to provide diagnostic clarification through a biopsychosocial formulation that addresses developmental issues and guides evidence-based treatment. Although diagnostic shift can occur, studies have demonstrated diagnostic stability of $70 \%$ at both 12 months (Addington 2006) and 18 months (Schimmelmann 2005) after thorough initial assessment, with diagnostic consistency of over $90 \%$ for schizophrenia.

Choosing the best time to discuss the diagnosis with patients and their families is important. Prematurely 'labelling' a patient with a diagnosis of schizophrenia before they have had a chance to process their experience and its implications is countertherapeutic. The diagnosis should be conveyed sensitively in a non-stigmatising manner and framed in hopeful and optimistic terms. Nevertheless, there should be a full and frank discussion on the nature of the illness and what the patient can do to achieve the best prognosis, for example cease substance misuse (Wade 2006a), adhere to medication regimens (Malla 2006) and engage in psychosocial interventions (Petersen 2008).

\section{Diagnostic confounders}

Drug-induced psychosis is a spurious term and many patients initially diagnosed with substanceinduced psychosis ultimately receive a diagnosis
BOX 1 Engagement techniques in first-episode psychosis

$\begin{array}{ll}\begin{array}{l}\text { - Treat the young person as responsible and } \\ \text { capable of having some say in decision- }\end{array} & \begin{array}{l}\text { - Find common ground between what } \\ \text { they want and need; tailor goals to the } \\ \text { making }\end{array} \\ \begin{array}{ll}\text { - Show genuine interest in the young person } \\ \text { and their explanatory model }\end{array} & \begin{array}{l}\text { - Be flexible: be prepared to see the young } \\ \text { person outside of traditional hospital }\end{array} \\ \text { - Express concern for their safety and well- } & \text { settings, e.g. their workplace, cafe, school } \\ \text { being; reduce anxiety by normalising the } & \text { - Be kind, empathic, open, firm, fair, } \\ \text { experience } & \text { consistent, non-judgemental and non- } \\ \text { - Be calm, reassuring, professional and } & \text { authoritarian: be engaging! } \\ \text { friendly } & \text { - Ensure you have been understood } \\ \text { - Clarify the young person's expectations } & \text { - Aim for routine and order, to reflect } \\ \text { and what they want } & \text { containment } \\ \text { - Provide a clear, concise explanation of } & \text { - Do not give up: maintain a consistent } \\ \text { their illness, avoiding jargon } & \text { approach in the face of rejection }\end{array}$

of schizophrenia (Mathias 2008). For example, in one study $44.5 \%$ of people initially presenting with cannabis-induced psychosis were subsequently diagnosed with a schizophrenia-spectrum disorder (Arendt 2005). The term 'drug-precipitated' may be more appropriate in cases where substance misuse is involved.

Agitation in non-affective first-episode psychosis is easily mistaken for signs of a true affective disturbance. This results in initial misclassification to bipolar affective disorder or schizoaffective disorder and inappropriate treatment with mood stabilisers. These drugs are often continued in the out-patient clinic, adding to side-effect burden and contributing to non-adherence. Clearly, true affective disturbance may merit treatment with mood stabilisers. Non-affective excitement can be treated with judicious use of benzodiazepines that can be subsequently discontinued. Secondary consultation with a psychiatrist specialising in first-episode psychosis may be sought to assist the differentiation of agitation from affective illness.

\section{Treatment}

Treatment is coordinated by a case manager within a multidisciplinary team. The team delivers a phase-oriented focus on early detection, recovery and relapse prevention, while minimising disability and secondary comorbidity. Aims of treatment are phase specific, varying according to the phase of the illness, and they include the following components.

\section{Antipsychotic medication}

Medication should be used at doses that maximise therapeutic benefit and adherence while minimising side-effects. Atypical antipsychotics remain the mainstay of treatment, despite recent 
§For recent discussions of clozapine use in Advances, see Mortimer AM (2011) Using clozapine in clinical practice, 17: 256-265; Mistry H, Osborn D (2011) Underuse of clozapine in treatment-resistant schizophrenia, 17: 250-255. Ed.
${ }^{\ddagger}$ For a discussion in Advances of the USA approach, see Schleifer JF (2011) Management of acute agitation in psychosis: an evidence-based approach in the USA, 17: 91-100. Ed guidelines (National Collaborating Centre for Mental Health 2009) recanting a preference for atypical antipsychotics shown in an earlier iteration (National Institute for Health and Clinical Excellence 2002). Either way, the tenet of 'start low, go slow' is well established. During the acute phase, safety of the patient, staff and family is paramount and medication for behavioural control should be used judiciously.

\section{Acute disturbance}

Algorithms for pharmacological management of acute disturbance ${ }^{\ddagger}$ vary. However, oral medication should generally be offered before parenteral treament and benzodiazepines before antipsychotics. The antipsychotic dose required for behavioural control is invariably higher than that needed for resolution of psychosis, yet the two doses are often conflated on discharge from inpatient units, leading to increased side-effects and non-adherence. Antipsychotics take 10-14 days for therapeutic response, and rapidly increasing the dose or changing medication will not shorten this process and again is likely to lead to increased side-effects and non-adherence.

Antipsychotic-naive patients, patients with slow hepatic metabolism or intellectual disability, and those under 18 years of age are most at risk of iatrogenic harm from antipsychotics. A blood test is now available to detect slow metabolisers and it should be carried out routinely in all patients on first presentation. In known or suspected cases of true affective disturbance, mood stabilisers may be used.

\section{Duration of medication}

While recommendations regarding length of antipsychotic treatment in first-episode psychosis remain ill-defined, best practice guidelines recommend a minimum of 1 year (e.g. Orygen Youth Health 2004). Given the high rate of relapse (Huber 2008), it is likely that the majority of patients need in excess of this. For example, those with schizophrenia are likely to benefit from ongoing antipsychotic medication throughout the first 3-5 years of their illness, commensurate with the 'critical period' (Birchwood 1998). Selecting which patients may benefit from guided discontinuation of their antipsychotic medication remains an inexact science and requires further research (Wunderink 2007). Practitioners should follow best practice treatment algorithms for affective and non-affective psychosis such as the Maudsley Prescribing Guidelines (Taylor 2011), switching patients as early as possible when nonresponse is apparent.
Non-response, clozapine ${ }^{\S}$ and depot antipsychotics

Treatment failure needs to be addressed early. Clozapine should be used if positive symptoms associated with functional distress persist after clear failures of two different antipsychotics. There is an argument that earlier use may ameliorate treatment resistance and reduce suicidality, but this must be weighed against the risk of significant side-effects. It is important not to seek to remove all positive symptoms at the expense of iatrogenicity, including negative symptoms. The delicate process of balancing engagement with minimising the DUP in patients resisting treatment can be helped by user-friendly psychoeducation, reducing the need for depot medication. A significant minority of patients will still require depot medication, although with continuing engagement and psychoeducation the majority of these would be expected to switch to oral treatment. Almost 20\% of people with first-episode psychosis persistently refuse medication, especially those with comorbid substance misuse, a forensic history, low insight and poor premorbid functioning (Lambert 2010). Such patients are likely to require more intensive assertive community treatment (Crlenjak 2008).

\section{Side-effects and polypharmacy}

Medication side-effects can be minimised by using minimum effective dose strategies, testing for slow metabolisers and attending to the patient's complaints. Polypharmacy should be minimised in accordance with treatment algorithms: there is a dearth of evidence regarding the efficacy of multiple antipsychotics and the rationale for such use should be clearly documented. The advent of atypical antipsychotics has challenged the use of adjunct medication to manage side-effects: patients who develop significant side-effects should have a change of antipsychotic unless there is a compelling, clearly recorded reason against this.

\section{Treatment of specific comorbid conditions}

Comorbid conditions are common in first-episode psychosis. They are associated with poorer outcomes (Power 1999) and require targeted evidence-based intervention.

\section{Depression}

Depression can occur during the prodromal phase, during acute psychosis and relapse, or in the aftermath of an acute episode (Birchwood 2009). It can be exacerbated by antipsychotic medication, substance misuse, the presence of negative symptoms and the recovery of insight. Prevalence rates vary depending on study criteria (Koreen 1993), but may be as high as $80 \%$ (Upthegrove 2010). 
Standard treatment algorithms for depression that include medication and cognitive-behavioural therapy (CBT) are appropriate.

Depression in the early stages of psychosis is a key factor in the development of suicidal ideation (Upthegrove 2010), highlighting the value of early treatment in reducing suicide. Other factors associated with increased suicide risk include male gender, unemployment and manic symptoms in the year following presentation (Dutta 2011). Although suicide remains a serious problem in schizophrenia, the commonly accepted estimated lifetime risk of $10 \%$ (Miles 1977) has been challenged in more recent years. One study reported a rate of $4.9 \%$ among new-onset and newly treated cohorts (Palmer 2005). Another reported rates of $1.9 \%$ in 2723 individuals with first-episode psychosis over a mean follow-up period of 11 years (Dutta 2010). As expected, the suicide rate was highest in the first year after presentation, although risk continued, with a median time to suicide of 5.6 years. Despite these lower figures, suicide attempts remain high in prodromal and first-episode cohorts, with rates of nearly $26 \%$ reported (Barrett 2010). A specific manualised CBT intervention has been developed to address suicidal ideation among people with first-episode psychosis (Power 2003), in addition to intensified case management (Crlenjak 2008).

\section{Substance misuse}

As well as increasing the risk of psychosis (e.g. Moore 2007), substance use disorders worsen the prognosis in first-episode psychosis patients (Green 2004; Wade 2006a; Petersen 2008), among whom use is high (Wade 2006b). Depression and persisting positive symptoms are more likely, and assertive interventions should be used to target this comorbid disorder (Edwards 2006; Turkington 2009). Healthcare professionals in all settings should routinely ask young people with known or suspected psychosis about any substance misuse, and further assessment and treatment should be offered in stigma-free environments (Kendall 2011). There is increasing recognition that specialised substance misuse clinicians should be embedded within youth mental health services (Lubman 2003; Barrowclough 2009), although standard evidenced-based treatments for substance misuse suffice for this cohort (Kendall 2011).

\section{Anxiety disorders}

Of the anxiety disorders, social anxiety disorder and post-traumatic stress disorder (PTSD) are the most common comorbid conditions in first-episode psychosis (Pokos 2006). Social anxiety disorder constitutes a significant problem, with rates of up to $25 \%$ reported (Michail 2009). Reported rates of PTSD secondary to traumatic elements of the episode (including psychotic symptoms, involuntary admission and police involvement) have been found to range from 20 to $39 \%$ (Mueser 2010; Sin 2010). Both require effective early treatment using standard evidence-based interventions.

\section{Neurodevelopmental disorders}

Autism-spectrum disorders and psychosis are considered separate entities, although there is considerable comorbidity and diagnostic overlap (Nylander 2008; Hofvander 2009). Emerging evidence of a shared neurodevelopmental pathway from genetic (O’Donovan 2008; Carroll 2009; McCarthy 2009) and neuropsychological (May 2011) studies suggests that autism-spectrum disorders can be a risk factor for schizophrenia.

It can be difficult to differentiate psychosis from autistic phenomena and to balance antipsychotic and behavioural interventions. Therefore, the recommendations of a specialist in autismspectrum disorders should be sought (Fraser 2011).

Individuals with attention-deficit hyperactivity disorder (ADHD) treated with amphetamine-like stimulants may be at increased risk of psychosis (Berman 2009; Karatekin 2009; Mosholder 2009). It is also possible that the ADHD embraces a group of children exposed to social adversity, which may itself act as a risk factor for schizophrenia. Where both ADHD and first-episode psychosis are present, amphetamine-like stimulants are contraindicated.

\section{Intellectual disability}

Individuals with intellectual disability (IQ < 70) are at higher risk of schizophrenia and other psychotic disorders than the general population (Bouras 2004; Nettelbladt 2009), with pregnancy and birth complications likely to be relevant aetiological factors in psychosis (O’Dwyer 1997). Diagnosis benefits from specialist input from intellectual disability services, and shared care is essential in achieving good outcomes. People with intellectual disabilities are more sensitive to the cognitive, extrapyramidal and prolactin-inducing side-effects of antipsychotics and are generally prescribed lower doses (Frighi 2011).

Not only are individuals with schizophrenia more likely to have premorbid intellectual impairment (Zammit 2004; Reichenberg 2005), but also those with normal premorbid IQs have lower mean IQs than the general population (Woodberry 2008) and are more likely to exhibit premorbid cognitive 
abnormalities (Brewer 2006b; Reichenberg 2006). Furthermore, premorbid IQ correlated with functional outcome in 3- (Leeson 2009) and 10year (van Winkel 2007) follow-up studies of firstepisode psychosis cohorts, although the 10-year study failed to demonstrate progressive cognitive deterioration: those with moderate baseline deficits tended to 'catch up' and improve over the course of the illness, whereas those with the most severe cognitive impairments at baseline showed no change (van Winkel 2006).

Cognitive remediation (McGurk 2007) and cognitive compensation therapies (Twamley 2003) are the current exemplars for treating cognitive deficits. It is an expanding area of research interest, with pharmacological (Green 2007) and cognitivebased interventions likely to flourish over the next decade. First-episode psychosis services should resource clinical neuropsychologists to provide such specialist input (Allott 2011).

\section{Personality disorders}

The presence of schizoid, paranoid or schizotypal personality disorder is likely to be an early manifestation of the disease process rather than a risk factor per se. Their premorbid presence not only makes a diagnosis of schizophrenia more likely, but also suggests a poorer prognosis (Murphy 2010).

The presence of borderline personality disorder in first-episode psychosis presents a dilemma. It is our experience that the overwhelming majority of patients who present with both have a history of childhood trauma. Severe adverse childhood experiences, including sexual, physical, psychological and emotional abuse and emotional neglect, are known to have damaging long-term consequences, including depression, PTSD, personality disorders, and drug and alcohol dependence (Morgan 2007a). However, the nexus with psychosis remains uncertain. Despite a review concluding that childhood abuse is a causal factor in psychosis generally and schizophrenia specifically (Read 2005), a subsequent review urged caution in interpreting the literature, concluding that it was inconsistent and marred by methodological limitations (Morgan 2007a).

The link is certainly plausible and has already been reported in bipolar affective disorder (Etain 2008). Certain risk factors for psychosis, including a first- or second-degree history of migration and urban dwelling, may be acting as proxy measures of early childhood adversity. It is likely that other traumatic events, such as bullying (Kelleher 2008; Schreier 2009) and parental separation (Morgan 2007b), are also implicated. Self-reports of childhood trauma have been shown to be both frequent (Conus 2010) and reliable (Fisher 2011) among people with first-episode psychosis.

Thus, the connections between borderline personality disorder and psychosis are manifold. We have identified factors that can be used to place patients into one of four groups, listed in Box 2. Individual patients can belong to more than one of these groups, but broad treatment recommendations can nonetheless be made.

The first group clearly need long-term antipsychotic treatment, in addition to therapy aimed at addressing childhood trauma. The second group also need both, although they are likely to require briefer antipsychotic treatment. In our experience, the third group benefit from a combination of trauma therapy and targeted antipsychotic medication during periods of stress which is withdrawn when the stress has been alleviated. The final group, those with dissociative symptoms, can benefit from antipsychotics as major tranquillisers (though at considerable sideeffect cost), but the mainstay of treatment should be evidence-based trauma therapy.

Unfortunately, first-episode psychosis services tend to overemphasise psychosis at the expense of trauma, tending to classify all patients as belonging to the first group. Misclassification as schizophrenia results in inappropriate exposure to antipsychotics while ignoring the trauma therapy that should constitute the main focus.

Treatment of externalised antisocial personality traits in first-episode psychosis involves working with the individual to maximise their sense of control. This includes engagement within a predictable, routine structure, whereby the

BOX 2 Factors associating borderline personality disorder and psychosis

1 Individuals with schizophrenia may have had traumatic childhood experiences and have premorbid borderline personality traits or borderline personality disorder

2 Individuals with borderline personality disorder are more likely to engage in substance misuse and are consequently at higher risk of drug-precipitated psychosis

3 Given the nature of the childhood abuse they have been exposed to, those with borderline personality disorder are more likely to be mistrustful of others and suffer a lower threshold for persecutory ideation, resulting in brief episodes of paranoia when under stress

4 The boundary between dissociative phenomena and true psychotic symptoms is difficult to demarcate, resulting in misdiagnosis of the former for the latter 
individual is encouraged to recognise triggers for anger, the impact of trauma during development and reliance on substances to ameliorate distress (Brewer 2008).

Careful history-taking of the development of behaviour likely to attract the attention of the criminal justice system is paramount for ascertaining risk of assault, with interventions involving secondary consultation with forensic psychiatrists.

\section{Psychological therapies}

Specific CBT-based interventions have been developed for a number of focused treatments. For example, teams at Orygen Youth Health in Melbourne, Australia, have developed interventions for: adjusting to the first episode (Henry 2002), relapse prevention (Gleeson 2009), treatment resistance (Herrmann-Doig 2003), cannabis use (Hinton 2002), suicide risk (Power 2003), bipolar disorder (MacNeil 2009), and comorbid antisocial traits (Brewer 2011).

Adherence therapy is an essential component of early psychosis intervention. Even brief periods of non-adherence to antipsychotic regimens lead to a greater risk of relapse in the course of early psychosis, and patients should be cautioned about the possible consequences of partial adherence and brief non-adherence (Subotnik 2011).

Working with young people to overcome their fears and prejudices about medication should occur in the context of a therapeutic relationship. Medication should be viewed as one aspect of a multimodal integrated approach to treatment. Common psychological barriers to adherence include fears concerning side-effects, loss of control, what antipsychotic medication means to the person in the context of a family history of psychosis, and the possibility of lifelong treatment (Kulkarni 1999). Patients should be afforded as much power in decision-making as possible, commensurate with mental state. Given that, clozapine aside, atypical antipsychotics are equally efficacious for positive symptoms, it is common practice to discuss side-effect profiles and allow patients to make an informed choice. Other strategies that may increase adherence include family involvement (Rabinovitch 2009), side-effect management, avoidance of polypharmacy, oncea-day dosing, orally disintegrating tablets and adherence therapy (Miller 2008).

\section{Psychosocial interventions}

As adolescence is characterised by a steep developmental trajectory, it is crucial to expedite functional recovery in young people with first-episode psychosis. Psychosocial interventions include vocational and educational support, family interventions, multimodal group programmes and the provision of psychoeducation and peer support workers; these appear to be more effective in first-episode cohorts than in people with chronic psychosis (Killackey 2009). Other aspects include assistance with accommodation, legal and forensic issues, culturally and linguistically sensitive practice, and liaison with community agencies.

\section{Framing recovery}

Much of the business of first-episode psychosis services involves helping patients to construct a narrative of their illness. This should include a shared understanding of the contribution of biological and environmental risk factors, together with early warning signs of decompensation within a stress-vulnerability model. In addition to the fact that many patients report childhood trauma, the episode itself is often reported as traumatic (McGorry 1991), so much so that a specific CBT intervention has been developed to assist recovery (Jackson 2009). Many patients are embarrassed, traumatised and overwhelmed by their early episodes, triggering a natural tendency to 'seal over' rather than attempt to integrate their experience (Tait 2004). This is an issue that the therapist must sensitively though robustly address, for example through establishing a predictable style of engagement that initially focuses on concrete problem-solving.

\section{Family involvement}

Many young people with first-episode psychosis are living with their parents or remain significantly involved with them and it is an ethical dilemma deciding on the amount of family involvement when a patient resists their input. First-episode psychosis services generally err in favour of engaging (often traumatised) families in such cases, although negotiating the amount of disclosure is guided by the patient's legal age, level of maturity, mental state and insight, and the functionality and degree of family involvement. Common family fears that need to be addressed include being blamed for the illness or for not recognising it at an earlier stage, being blamed by the young person for their admission to hospital, and the negative impact of medication. Allaying these often unstated fears may require repeated information given by different clinicians at different contacts.

\section{Phase-specific treatment}

Phase-specific treatment along clinical pathway algorithms optimises recovery. Exposure to evidence-based psychotherapies and medication is 
best titrated by phase of illness and associated risks, with the caveat that $80 \%$ of patients ultimately relapse (Alvarez-Jiménez 2009). Full and frank discussions about diagnosis and risk of relapse are as important as those aimed at instilling hope. Likewise, it is important to recognise early signs of treatment resistance and treat assertively. It is theoretically possible that early use of clozapine could circumvent treatment resistance and allow subsequent treatment with regular atypical antipsychotics. Treatment of negative symptoms poses a particular challenge owing to the lack of efficacious interventions (Murphy 2006), and early recognition is paramount, with evidence-based approaches embedded into clinical pathways.

\section{Community liaison}

Engaging community services is vital for shared care and seamless discharge. It is important that first-episode psychosis services support such agencies, providing effective communication and primary and secondary consultation as necessary. Community liaison should also include community awareness campaigns directed at the general public, general practitioners, police, schools and colleges. First-episode psychosis services need to negotiate division of responsibility for sexual and physical health with primary care providers; cardiometabolic risks are evident early and this period may be critical for intervention (Foley 2011). Although a range of interventions are available, the single most effective is likely to be avoidance of weight-gaining antipsychotics.

\section{Conclusions}

Engagement, assessment and early intervention are critical in optimising the outcome of people experiencing a first episode of psychosis. A holistic treatment package should be offered in stigma-free settings, incorporating low-dose antipsychotics, psychological therapies, treatment of comorbid mental and physical illnesses, vocational and educational services, family support and multimodal group programmes.

\section{References}

Addington J, Chaves A, Addington D (2006) Diagnostic stability over one year in first-episode psychosis. Schizophrenia Research 86: 71-5.

Allott K, Brewer W, McGorry PD, et al (2011) Referrers' perceived utility and outcomes of clinical neuropsychological assessment in an adolescent and young adult public mental health service. Australian Psychologist 46: 15-24.

Alvarez-Jiménez M, Parker AG, Hetrick SE, et al (2011) Preventing the second episode: a systematic review and meta-analysis of psychosocial and pharmacological trials in first-episode psychosis. Schizophrenia Bulletin 37: 619-30.
Amminger GP, Harris MG, Conus P, et al (2006) Treated incidence of firstepisode psychosis in the catchment area of EPPIC between 1997 and 2000. Acta Psychiatrica Scandinavica 114: 337-45.

Arendt M, Rosenberg R, Foldager L, et al (2005) Cannabis-induced psychosis and subsequent schizophrenia-spectrum disorders: follow-up study of 535 incident cases. British Journal of Psychiatry 187: 510-5.

Barrett EA, Sundet K, Faerden A, et al (2010) Suicidality before and in the early phases of first episode psychosis. Schizophrenia Research 119: 11-7

Barrowclough C, Haddock G, Beardmore R, et al (2009) Evaluating integrated $\mathrm{Ml}$ and CBT for people with psychosis and substance misuse: recruitment, retention and sample characteristics of the MIDAS trial. Addictive Behaviors 34: 859-66.

Berman SM, Kuczenski R, McCracken JT, et al (2009) Potential adverse effects of amphetamine treatment on brain and behavior: a review. Molecular Psychiatry 14: 123-42.

Birchwood M, Todd P, Jackson C (1998) Early intervention in psychosis: the critical period hypothesis. British Journal of Psychiatry 172 (suppl 33): s53- 9 .

Birchwood M, Gleeson J, Chanen A, et al (2009) Emotional and personality dysfunctions in early psychosis. In The Recognition and Management of Early Psychosis: A Preventative Approach (2nd edn) (eds HJ Jackson, PD McGorry): 283-302. Cambridge University Press.

Bouras N, Martin G, Leese M, et al (2004) Schizophrenia-spectrum psychoses in people with and without intellectual disability. Journal of Intellectual Disability Research 48: 548-55.

Brewer WJ Wood SJ, DeLuca C et al (2006a) Olfactory processing and brain maturation. In Olfaction and the Brain (eds WJ Brewer, D Castle, C Pantelis): 103-18. Cambridge University Press.

Brewer WJ, Wood SJ, Phillips LJ, et al (2006b) Generalised and specific cognitive performance in clinical high-risk cohorts: a review highlighting potential vulnerability markers for psychosis. Schizophrenia Bulletin 32 : 538-55

Brewer WJ, Gleeson J, Gee D, et al (2008) Prevalence of antisocial personality traits and disorder in first episode psychosis cohorts. Early Intervention in Psychiatry 2: A42.

Brewer WJ (2011) First Episode Psychosis: Antisocial Personality Intervention Manual. EPPIC.

Carroll LS, Owen MJ (2009) Genetic overlap between autism, schizophrenia and bipolar disorder. Genome Medicine 1: 102.

Crlenjak C, Gee D, Duff C, et al (2008) Engaging high suicide risk early psychosis clients via intensive case management. 6th International Conference on Early Psychosis, Melbourne. Early Intervention in Psychiatry 2 (suppl 1): A82.

Conus P, Cotton S, Schimmelmann BG, et al (2010) Pretreatment and outcome correlates of sexual and physical trauma in an epidemiological cohort of first-episode psychosis patients. Schizophrenia Bulletin 36: 1105-14.

Dutta R, Murray RM, Hotopf M, et al (2010) Reassessing the long-term risk of suicide after a first episode of psychosis. Archives of General Psychiatry 67: 1230-7

Dutta R, Murray RM, Allardyce J, et al (2011) Early risk factors for suicide in an epidemiological first episode psychosis cohort. Schizophrenia Research 126: 11-9.

Edwards J, Elkins K, Hinton M, et al (2006) Randomized controlled trial of a cannabis-focused intervention for young people with first-episode psychosis. Acta Psychiatrica Scandinavica 114: 109-17.

Etain B, Henry C, Bellivier F, et al (2008) Beyond genetics: childhood affective trauma in bipolar disorder. Bipolar Disorders 10: 867-76.

Fisher HL, Craig TK, Fearon P, et al (2011) Reliability and comparability of psychosis patients' retrospective reports of childhood abuse. Schizophrenia Bulletin 37: 546-53.

Foley DL, Morley KI (2011) Systematic review of early cardiometabolic outcomes of the first treated episode of psychosis. Archives of General Psychiatry 68: 609-16. 
Fraser R, Angus B, Cotton S, et al (2011) Prevalence of autism spectrum conditions in a youth mental health service. Australian and New Zealand Journal of Psychiatry 45: 426

Frighi V, Stephenson MT, Morovat A, et al (2011) Safety of antipsychotics in people with intellectual disability. British Journal of Psychiatry 199: 289-95.

Gleeson JF, Cotton SM, Alvarez-Jimenez M (2009) A randomized controlled trial of relapse prevention therapy for first-episode psychosis patients. Journal of Clinical Psychiatry 70: 477-86.

Green Al, Tohen MF, Hamer RM, et al (2004) First episode schizophreniarelated psychosis and substance use disorders: acute response to olanzapine and haloperidol. Schizophrenia Research 66:125-35.

Green MF (2007) Stimulating the development of drug treatments to improve cognition in schizophrenia. Annual Review of Clinical Psychology 3: $159-80$

Henry L, Edwards J, Jackson H, et al (2002) Cognitively Oriented Psychotherapy for First-Episode Psychosis (COPE): A Practitioner's Manual. EPPIC.

Herrmann-Doig T, Maude D, Edwards J (2003) Systematic Treatment of Persistent Psychosis. Martin Dunitz.

Hinton M. Elkins K. Edwards J, et al (2002) Cannabis and Psychosis: An Early Psychosis Treatment Manual. Melbourne: EPPIC.

Hofvander B, Delorme R, Chaste P, et al (2009) Psychiatric and psychosocial problems in adults with normal-intelligence autism spectrum disorders. BMC Psychiatry 9: 35 .

Huber CG, Naber D, Lambert M (2008) Incomplete remission and treatment resistance in first-episode psychosis: definition, prevalence and predictors. Expert Opinion in Pharmacotherapy 9: 2027-38.

Jackson C, Trower P, Reid I, et al (2009) Improving psychological adjustment following a first episode psychosis: a randomized controlled trial of cognitive therapy to reduce post psychotic trauma symptoms. Behavior Research Therapy 47: 454-62.

Karatekin C, White T, Bingham C (2009) Shared and nonshared symptoms in youth-onset psychosis and ADHD. Journal of Attention Disorders 14: 121-31.

Kelleher I, Harley M, Lynch F, et al (2008) Associations between childhood trauma, bullying and psychotic symptoms among a school-based adolescent sample. British Journal of Psychiatry 193: 378-82.

Kendall T, Tyrer P, Whittington C, et al (2011) Assessment and management of psychosis with coexisting substance misuse: a summary of NICE guidance. BMJ 342 (Mar 23): d1351. doi: 10.1136/bmj.d1351.

Killackey E (2009) Psychosocial and psychological interventions in early psychosis: essential elements of recovery. Early Intervention in Psychiatry 3 (suppl 1): s17-21.

Koreen A, Siris S, Chakos M, et al (1993) Depression in first-episode schizophrenia. American Journal of Psychiatry 150: 1643-8.

Kulkarni J, Power P (1999) Initial treatment of first-episode psychosis. In The Recognition and Management of Early Psychosis: A Preventative Approach (eds PD McGorry, HJ Jackson): 184-205. Cambridge University Press.

Lambert M, Conus P, Cotton S, et al (2010) Prevalence, predictors, and consequences of long-term refusers of antipsychotic treatment in firstepisode psychosis. Journal of Clinical Psychopharmacology 30: 565-72.

Leeson VC, Barnes TR, Hutton SB, et al (2009) IO as a predictor of functional outcome in schizophrenia: a longitudinal, four-year study of first-episode psychosis. Schizophrenia Research 107: 55-60.

Lubman DI, Sundram S (2003) Substance misuse in patients with schizophrenia: a primary care guide. Medical Journal of Australia 178 (suppl 7): 1-5.

MacNeil C, Hasty MK, Conus P, et al (2009) Bipolar Disorder in Young People: A Psychological Intervention Manual. Cambridge University Press.

Malla A, Norman R, Schmitz N, et al (2006) Predictors of rate and time to remission in first-episode psychosis: a two-year outcome study. Psychological Medicine 36: 649-58.
Mathias S, Lubman D, Hides L (2008) Substance-induced psychosis: a diagnostic conundrum. Journal of Clinical Psychiatry 69: 358-67.

May T, Brewer WJ, Rinehart N, et al (2011) Differential olfactory identification in children with autism and Asperger's disorder: a comparative and longitudinal study. Journal of Autism and Developmental Disorders 41: 837-47.

McCarthy SE, Makarov V, Kirov G, et al (2009) Microduplications of 16p11.2 are associated with schizophrenia. Nature Genetics 41: 1223-7.

McCutcheon LK, Chanen AM, Fraser RJ, et al (2007) Tips and techniques for engaging and managing the reluctant, resistant or hostile young person. Medical Journal of Australia 187 (suppl 7): 64-7.

McGorry PD, Chanen A, McCarthy E, et al (1991) Posttraumatic stress disorder following recent-onset psychosis: an unrecognized postpsychotic syndrome. Journal of Nervous and Mental Disorders 179: 253-8.

McGorry PD, Hickie IB, Yung AR, et al (2006) Clinical staging of psychiatric disorders: a heuristic framework for choosing earlier, safer and more effective interventions. Australian and New Zealand Journal of Psychiatry 40: 616-22.

McGurk SR, Twamley EW, Sitzer DI, et al (2007) A meta-analysis of cognitive remediation in schizophrenia. American Journal of Psychiatry 164: 1791-802

Michail M, Birchwood M (2009) Social anxiety disorder in first-episode psychosis: incidence, phenomenology and relationship with paranoia. British Journal of Psychiatry 195: 234-41.

Miles CP (1977) Conditions predisposing to suicide. Journal of Nervous and Mental Disorders 164: 231-46.

Miller BJ (2008) A review of second-generation antipsychotic discontinuation in first-episode psychosis. Journal of Psychiatric Practice 14: 289-300.

Moore TH, Zammit S, Lingford-Hughes A, et al (2007) Cannabis use and risk of psychotic or affective mental health outcomes: a systematic review. Lancet 370: 319-28.

Morgan C, Fisher H (2007a) Environmental factors in schizophrenia: childhood trauma - a critical review. Schizophrenia Bulletin 33: 3-10.

Morgan C, Kirkbride J, Leff J, et al (2007b) Parental separation, loss and psychosis in different ethnic groups: a case-control study. Psychological Medicine 37: 495-503.

Mosholder AD, Gelperin K. Hammad TA, et al (2009) Hallucinations and other psychotic symptoms associated with the use of attention-deficit/ hyperactivity disorder drugs in children. Pediatrics 123: 611-6.

Mueser KT, Lu W, Rosenberg SD, et al (2010) The trauma of psychosis: posttraumatic stress disorder and recent onset psychosis. Schizophrenia Research 116: 212-27.

Murphy BP (2010) Beyond the first episode: candidate factors for a risk prediction model of schizophrenia. International Review of Psychiatry; 22: 202-23.

Murphy B, Brewer W (2011) Early intervention in psychosis: strengths and limitations of services. Advances in Psychiatric Treatment 17: 401-7.

Murphy B, Chung Y-C, McGorry PD (2006) Pharmacological treatment of primary negative symptoms in schizophrenia: a systematic review. Schizophrenia Research 88: 5-25.

National Collaborating Centre for Mental Health (2009) Schizophrenia: Core Interventions in the Treatment and Management of Schizophrenia in Adults in Primary and Secondary Care (Update) (NICE Clinical Guideline 82). National Institute for Health and Clinical Excellence.

National Institute for Health and Clinical Excellence (2002) Guidance on the Use of Newer (Atypical) Antipsychotic Drugs for the Treatment of Schizophrenia (NICE Technology Appraisal Guidance 43). NICE.

Nettelbladt P, Göth M, Bogren M, et al (2009) Risk of mental disorders in subjects with intellectual disability in the Lundby cohort 1947-97. Nordic Journal of Psychiatry 63: 316-21.

Nylander L (2008) Autism spectrum disorders and schizophrenia spectrum disorders - is there a connection? A literature review and some suggestions for future clinical research. Clinical Neuropsychiatry 5: 43-54.

\section{MCO answers \\ $1 b \quad 2 d \quad 3 b \quad 4 b \quad 5 a$}


O'Donovan MC, Kirov G, Owen MJ (2008) Phenotypic variations on the theme of CNVs. Nature Genetics 40: 1392-3.

O’Dwyer JM (1997) Schizophrenia in people with intellectual disability: the role of pregnancy and birth complications. Journal of Intellectual Disability Research 41: 238-51.

Orygen Youth Health (2004) The Acute Phase of Early Psychosis: A Handbook on Management. Orygen Research Centre.

Palmer BA, Pankratz VS, Bostwick JM (2005) The lifetime risk of suicide in schizophrenia: a reexamination. Archive of General Psychiatry 62: 247-53.

Petersen L, Thorup A, Øqhlenschlaeger J, et al (2008) Predictors of remission and recovery in a first-episode schizophrenia spectrum disorder sample: 2-year follow-up of the OPUS trial. Canadian Journal of Psychiatry 53: 660-70.

Pokos V, Castle DJ (2006) Prevalence of comorbid anxiety disorders in schizophrenia spectrum disorders: a literature review. Current Psychiatry Reviews 2: 285-307.

Power P, McGorry PD (1999) Suicide and early psychosis. In The Recognition and Management of Early Psychosis: A Preventative Approach (eds PD McGorry, HJ Jackson): 184-205. Cambridge University Press.

Power PJ, Bell RJ, Mills R, et al (2003) Suicide prevention in first episode psychosis: the development of a randomised controlled trial of cognitive therapy for acutely suicidal patients with early psychosis. Australian and New Zealand Journal of Psychiatry 37: 414-20.

Rabinovitch M, Bechard-Evans L, Schmitz N, et al (2009) Early predictors of non-adherence to antipsychotic therapy in first-episode psychosis. Canadian Journal of Psychiatry 54: 28-35

Read J, van Os J, Morrison AP, et al (2005) Childhood trauma, psychosis, and schizophrenia: a literature review with theoretical and clinical implications. Acta Psychiatrica Scandinavica 112: 330-50.

Reichenberg A (2005) Cognitive impairment as a risk factor for psychosis. Dialogues in Clinical Neuroscience 7: 31-8.

Reichenberg A, Weiser M, Rapp MA (2006) Premorbid intra-individual variability in intellectual performance and risk for schizophrenia: a population-based study. Schizophrenia Research 85: 49-57.

Schimmelmann BG, Conus P, Edwards J, et al (2005) Diagnostic stability 18 months after treatment initiation for first-episode psychosis. Journal of Clinical Psychiatry 66: 1239-46.

Schreier A, Wolke D, Thomas K, et al (2009) Prospective study of peer victimization in childhood and psychotic symptoms in a nonclinical population at age 12 years. Archives of General Psychiatry 66: 527-36.

Sin GL, Abdin E, Lee J, et al (2010) Prevalence of post-traumatic stress disorder in first-episode psychosis. Early Intervention in Psychiatry 4: 299-304.
Spear LP (2000) The adolescent brain and age-related behavioral manifestations. Neuroscience \& Biobehavioral Reviews 24: 417-63.

Steinberg L (2005) Cognitive and affective development in adolescence. Trends in Cognitive Science 9: 69-74.

Subotnik KL, Nuechterlein KH, Ventura J (2011) Risperidone nonadherence and return of positive symptoms in the early course of schizophrenia. American Journal of Psychiatry 168: 286-92.

Tait L, Birchwood B, Trower P (2004) Adapting to the challenge of psychosis: personal resilience and the use of sealing-over (avoidant) coping strategies. British Journal of Psychiatry 185: 410-5

Taylor D, Paton C, Kapur S (2011) The Maudsley Prescribing Guidelines in Psychiatry (11th edn). Wiley-Blackwell.

Turkington A, Mulholland CC, Rushe TM, et al (2009) Impact of persistent substance misuse on 1-year outcome in first-episode psychosis. British Journal of Psychiatry 195: 242-8.

Twamley EW, Jeste DV, Bellack AS (2003) A review of cognitive training in schizophrenia. Schizophrenia Bulletin 29: 359-82.

Upthegrove R, Birchwood M, Ross K, et al (2010) The evolution of depression and suicidality in first episode psychosis. Acta Psychiatrica Scandinavica 122: 211-8.

van Winkel R, Myin-Germeys I, Delespaul P, et al (2006) Premorbid IO as a predictor for the course of $\mathrm{IQ}$ in first onset patients with schizophrenia: a 10-year follow-up study. Schizophrenia Research 88: 47-54.

van Winkel R, Myin-Germeys I, De Hert M, et al (2007) The association between cognition and functional outcome in first-episode patients with schizophrenia: mystery resolved? Acta Psychiatrica Scandinavica 116: 119-24

Wade D, Harrigan S, Edwards J, et al (2006a) Substance misuse in firstepisode psychosis: 15-month prospective follow-up study. British Journal of Psychiatry 189: 229-34.

Wade D, Harrigan S, Edwards J, et al (2006b) Course of substance misuse and daily tobacco use in first-episode psychosis. Schizophrenia Research 81: $145-50$.

Woodberry KA, Giuliano AJ, Seidman LJ (2008) Premorbid I0 in schizophrenia: a meta-analytic review. American Journal of Psychiatry 165: 579-87.

Wunderink L, Nienhuis FJ, Sytema S, et al (2007) Guided discontinuation versus maintenance treatment in remitted first-episode psychosis: relapse rates and functional outcome. Journal of Clinical Psychiatry 68: $654-61$

Zammit S, Allebeck P, David AS, et al (2004) A longitudinal study of premorbid 10 score and risk of developing schizophrenia, bipolar disorder, severe depression, and other nonaffective psychoses. Archives of General Psychiatry 61: 354-60.

\section{MCQs}

Select the single best option for each question stem

\section{Engagement techniques in first-episode} psychosis include:

a immediate recourse to police support

b clarifying what the young person wants

c predominantly using closed questions

d assuming that the young person has no

capacity for informed decision-making

e making a clear diagnosis at first contact.

\section{Two recent studies found diagnostic}

stability at 12 and 18 months to be:

a $40 \%$

b $50 \%$

c $60 \%$ d $70 \%$

e $80 \%$

3 Those least at risk of iatrogenic harm from antipsychotics are:

a slow hepatic metabolisers

b rapid hepatic metabolisers

c antipsychotic naive

$\mathrm{d}$ those with intellectual disability

e under 18 years of age. c unemployment

d depression

e mania.

5 Which of the following is not a specific focus for CBT interventions in firstepisode psychosis?

a family relationships

b relapse prevention

c cannabis use

d treatment resistance

e suicide risk. 